\title{
O DESIGNER INSTRUCIONAL E O DESIGNER EDUCACIONAL NO CAMPO DA EAD: CONCEITO E PRÁTICA
}

\author{
FLORIANOPOLIS/SC JUNHO/2018
}

\author{
Cíntia Costa Macedo - UFSC - cintiacm37@gmail.com \\ Juliana Cristina Faggion Bergmann - UFSC - juliana.bergmann@ufsc.br
}

Tipo: Investigação Científica (IC)

Natureza: Descrição de Projeto em Andamento

Categoria: Métodos e Tecnologias

Setor Educacional: EDUCAÇÃO SUPERIOR

\begin{abstract}
RESUMO
Na modalidade da Educação a Distância atuam diferentes perfis de profissionais e especialistas para o desenvolvimento dos cursos e materiais didáticos. O Designer Instrucional e o Designer Educacional são alguns destes especialistas, e sua atuação objetiva o tratamento desses conteúdos didáticos para serem compreendidos e assimilados na linguagem e contexto das especificidades da virtualidade. No entanto, observa-se que em muitos casos os termos para se definir a estes profissionais são usados indiscriminadamente, independente de suas atribuições. Diante disso, este artigo apresenta um planejamento de pesquisa acadêmica para dissertação de mestrado que tem o intuito de discutir, a partir de algumas das diferentes teorias que circundam a atuação desses profissionais, suas características conceituais e práticas, a fim de conhecer suas atribuições e compreender se estamos diante do mesmo perfil ou se são profissionais distintos.
\end{abstract}

Palavras-chave: Designer Instrucional; Designer Educacional; Educação a Distância. 


\section{Introdução}

No âmbito da Educação a Distância $(\mathrm{EaD})$ há um profissional que atua diretamente nas fases de planejamento, desenvolvimento e implementação dos conteúdos didáticos necessários para um curso online, e que, por isso, tem sido objeto de vários estudos. $O$ Designer Instrucional (DI) e o Designer Educacional (DE) são profissionais que trabalham na adequação didática da linguagem de recursos de aprendizagem, na proposição de tecnologias e estratégias para facilitar o aprendizado e na adaptação do conteúdo à metodologia da Educação a Distância e da Instituição.

Para cumprir o tema aqui proposto, a questão principal que norteia este estudo é se há uma diferença conceitual e na ação pedagógica destes dois profissionais. E ainda, se há um consenso nacional sobre as atividades desempenhadas pelo DI e pelo DE, o seu papel e o perfil profissional. Em uma revisão dentre as bibliografias sobre o assunto, as terminologias designer instrucional e designer educacional, são utilizadas como sinônimos para o profissional que analisa, planeja, implementa e avalia os cursos de EaD e os materiais didáticos para esses cursos. Deste modo, a partir desta problemática, pretendemos refletir sobre o tema adentrando o universo do DI e do DE, com o intuito de compreender melhor as atribuições especificadas pelas instituições nas atuações destes profissionais.

Por esse motivo, o estudo proposto tem como principal característica investigar os aspectos que circundam o trabalho do DI e do DE, com o intuito de elucidar as dúvidas que ainda persistem sobre a dissociação do perfil e atuação destes profissionais, buscando aprofundar e dimensionar estratégias, a fim de promover uma comunicação efetiva entre os atores envolvidos na elaboração dos materiais e/ou desenvolvimento de cursos de Educação a Distância, e consequentemente, no aprendizado do estudante. Desse modo, este artigo apresenta aspectos importantes sobre estes profissionais, iniciando com as primeiras menções sobre a prática de desenvolvimento de materiais didáticos e tecnologia no país, passando para as principais áreas de conhecimento e atribuições requeridas para o DI e DE nos últimos anos e chegando então a reflexão sobre os perfis e práticas de atuação destes dois profissionais.

Contudo, esta pesquisa não pretende apenas estabelecer a diferença entre os termos, mas também, tendo como pano de fundo tais diferenças, (re)pensar o DI e o DE como sujeitos com especificidades e lugares distintos, porém no mesmo campo de atuação e refletir sobre o papel e/ou função desse sujeito integrador do desenvolvimento dos cursos na modalidade a distância. 


\section{Objetivos}

- Diferenciar a inserção do profissional do DI e DE no campo da EaD;

- Mapear as práticas desses profissionais no campo em que atuam.

- Especificar terminologicamente as nomenclaturas design, instrucional e educacional usadas para definir o designer de desenvolvimento de cursos e materiais didáticos.

- Investigar, através de entrevistas com os envolvidos na construção de materiais didáticos e cursos online, quais práticas exercem o DI ou DE em sua respectiva instituição.

\section{Referencial Teórico}

\subsection{O profissional no Brasil}

O início da prática instrucional voltada para o aprendizado está datado depois da Segunda Guerra Mundial, na década de 1950, em que estudiosos, psicólogos e educadores tiveram que treinar muitos soldados para manejar as sofisticadas armas militares da época. Para isso, desenvolveram treinamentos instrucionais baseados em vídeos inspirados pelo cinema.

No Brasil, não se sabe ao certo quando se iniciou exatamente a prática do profissional de design instrucional e educacional. Contudo, diante das pesquisas realizadas para traçar um histórico desse profissional no país, a primeira menção que temos da prática e literatura nacional é da Instrução Programada (IP). Sua base é regida nos estudos de Sidney Leavitt Pressey (1888 - 1979), na década de 1920, sobre a elaboração das máquinas de aprendizagem, ou ainda, dispositivos de ensino, e no condicionamento operante de Skinner (1904-1990), na década de 1930.

Outros vieses teóricos que surgiram na mesma época em nosso país foram os estudos sobre a Tecnologia Instrucional, Teorias da Instrução e a Tecnologia Educacional, datados do início da década de 1970, por João Batista Oliveira. O autor apresenta em um de seus livros um enfoque sistêmico aplicado à instrução, a fim de atender as necessidades da Tecnologia Educacional e os objetivos da educação. Oliveira (1974) ressaltava, que até aquele momento, existia uma inadequação das teorias de aprendizagem, o que dificultava a busca e a solução para os problemas de instrução. Dessa forma, apenas um enfoque sistêmico poderia suprir essa necessidade, pois forneceria recursos metodológicos adequados, a fim de construir um modelo de estudo que permitisse a integração dos diversos elementos que influenciam o processo de 
instrução.

Apesar de o autor entender que as áreas as quais tratam da instrução e educação (ou aprendizagem) possuem conceitos diferenciados, entendemos que para ele a instrução e a educação se convergem, ou seja, uma não se dá sem a outra. Porém, é importante frisar que, mesmo estando vinculadas, continuam sendo campos que devem ser entendidos separadamente, ressaltando que "se a distinção entre instrução e educação for aceita, fica claro que então estaremos tratando aqui de problemas relacionados com a tecnologia instrucional, e não com todos os aspectos de tecnologia educacional." (OLIVEIRA e OLIVEIRA, 1974 p. 10). Desse modo, entende-se que a tecnologia educacional apresenta uma gama de elementos que devem ser considerados em sua complexidade.

Importante destacarmos neste ponto que não foram encontrados referenciais sobre 0 profissional de design instrucional ou educacional, nas pesquisas realizadas nos teóricos brasileiros sobre Instrução Programada, Tecnologia Instrucional e Tecnologia Educacional até início da década de 1980. Assim, para o desenvolvimento de materiais didáticos nessa época, encontraram-se diferentes nomenclaturas para essa função com distintos perfis: professores que desenvolviam seu próprio material, especialistas em IP, projetistas voltados à área de Tecnologia da Informação, e, em alguns casos, principalmente em desenvolvimento de projetos de teleducação, eram elaborados e estudados por um grupo pré-determinado.

Em se tratando do primeiro registro de curso ofertado para a análise e elaboração de materiais didáticos, ressalta-se a Especialização (Lato-sensu) em Design Instrucional para cursos on-line, na Universidade Federal de Juiz de Fora, em 2005. Contudo, atualmente no país, são oferecidos diversos tipos de cursos para formação de DI e DE, como especializações, cursos rápidos e treinamentos, devido à grande procura por profissionais qualificados na área de EaD, tanto acadêmica como corporativa.

A regulamentação da profissão registrada na Classificação Brasileira de Ocupações (CBO), em 2008, está especificada como Designer Educacional, tendo o Designer Instrucional como sinônimo, assim como Desenhista instrucional e Projetista instrucional. A CBO descreve a função como:

Implementam, avaliam, coordenam e planejam o desenvolvimento de projetos pedagógicos/instrucionais nas modalidades de ensino presencial e/ou a distância, aplicando metodologias e técnicas para facilitar o processo de ensino e aprendizagem. Atuam em cursos acadêmicos e/ou corporativos em todos os níveis de ensino para atender as necessidades dos alunos, acompanhando e avaliando os processos educacionais. Viabilizam o trabalho coletivo, criando e organizando mecanismos de participação em programas e projetos educacionais, facilitando o processo comunicativo entre a comunidade escolar e as associações a ela vinculadas. (MINISTÉRIO 
DO TRABALHO, 2008).

Mais recentemente, no início de 2017, a Universidade Federal de São Paulo (UNIFESP), em parceria com a Universidade Aberta do Brasil (UAB), ofertou a primeira graduação tecnológica em Design Educacional do país, na modalidade a distância, com duração de cinco semestres e carga horária de 2.016 horas. Esse é um marco de inovação na área, trazendo uma valorização do profissional de designer instrucional e educacional.

\section{2 perfil do profissional}

Alguns teóricos acreditam que o designer deve possuir um perfil interdisciplinar, de modo a atender todos os requisitos que se esperam dele, desde a análise de um material didático, a comunicação interpessoal com professores e equipe, passando por características de gestão, planejamento e implementação, até a criatividade de desenvolvimento, criação e inovação de recursos didáticos tecnológicos. Embasando esta ideia, algumas definições para o DI e DE são encontradas na literatura nacional:

O DI é responsável não só pela elaboração dos cursos virtuais, mas por todas as fases desde o planejamento, desenvolvimento até a seleção da metodologia mais adequada, para que se possa atingir os objetivos educacionais propostos diante de cada contexto. (KENSKY; BARBOSA, 2007, p. 3).

Kenski e Barbosa entendem que o designer tem um perfil multifacetado, responsável tanto pela elaboração dos materiais, do planejamento, do desenvolvimento e pela escolha da metodologia que mais se adequa ao perfil dos estudantes e necessidades do projeto e objetivos do curso.

Nesse contexto, cabe perguntar: será possível encontrar um profissional com tantas características distintas? Em uma equipe multidisciplinar, para a concepção de cursos na modalidade a distância, um mesmo perfil de designer conseguirá atender tanto as questões de planejamento pedagógico, quanto aquelas pontuais de adequação e análise de materiais e recursos didáticos? Quais as características pessoais e a formação ideal que esse profissional deve possuir? Há uma diferença entre o Designer Instrucional e Designer Educacional?

Durante as pesquisa realizadas, observou-se que, algumas atividades atribuídas ao designer de desenvolvimento de cursos e materiais didáticos são:

- Análise e adequação da linguagem numa perspectiva dialógica de textos, livros didáticos, mídias interativas, recursos didáticos e do desenho pedagógico das unidades curriculares dos cursos, apontando alternativas para interatividade entre 
os aprendizes, professores e tutores no Ambiente Virtual de Ensino e Aprendizagem (AVEA);

- Elaboração e/ou análise de guias para a equipe multidisciplinar e professores;

- Revisão e análise do conteúdo e coerência visual do material didático produzido para os cursos e adaptá-lo para a modalidade a distância;

- Criação e roteirização de storyboard a partir de conteúdos específicos dos cursos.

- Roteirização de recursos educacionais como, webaulas, objetos de aprendizagem, quadrinhos, entre outros.

- Seleção de mídias e TDIC (tecnologias digitais de informação e comunicação) para utilização nos cursos, considerando as estratégias de ensino-aprendizagem, trabalhando diretamente com o revisor, com o diagramador e com toda a equipe audiovisual;

- Assessoria e acompanhamento do trabalho do professor/conteudista, tutores a distância e tutores presenciais e de laboratório, e participação das reuniões pedagógicas e dos trabalhos determinados pela coordenação do programa;

- Planejamento e implementação do curso juntamente com a coordenação, realizando o levantamento e análise de necessidades de instrução e ensino.

- Colaboração com a autoria na programação de estratégias de aprendizagem e avaliações.

- Desenvolvimento de Projetos Educacionais.

- Desenvolvimento de material didático acessível.

- Acompanhamento e orientação a professores durante a elaboração do conteúdo didático e recursos multimídia para as disciplinas;

- Formação de professores, de acordo com a metodologia da instituição de ensino.

\subsection{O designer instrucional e o designer educacional}

Entendendo que, a partir dos significados básicos das palavras instruir e educar, e partindo do pressuposto de instrução como ação de instruir e educação como ação de educar, percebe-se que, enquanto a instrução, em um primeiro momento, observada em um dicionário de norma linguística, é direcionada como sinônimo de educação, etimologicamente, de acordo com Cunha (2012), remete ao apontar, ao instrumento e à técnica. Já a educação, tanto no dicionário terminológico como no etimológico, traz a noção do didático, do pedagógico. O significado etimológico "conduzir para fora", dános a interpretação do novo olhar, de direcionar o estudante para outra situação diferente da atual. Podemos notar aqui, uma possível menção à reflexão crítica do estudante.

Assim, a partir das análises realizadas, percebeu-se que o perfil do designer instrucional 
está relacionado diretamente com a Tecnologia Instrucional e as peculiaridades que a norteiam, em que a instrução é a base para a prática, ou seja, a ação de comunicar para que o estudante seja instruído a aprender algo, de maneira que o seu conhecimento seja avaliado ao final do processo, em forma de desempenho. Nota-se que a instrução está inserida no processo educacional, sendo uma parte do complexo processo de aprendizado que o estudante necessita para poder atingir o conhecimento desejado.

No âmbito das métricas pré-determinadas para o desenvolvimento de materiais didáticos para $\mathrm{EaD}$, a linguagem instrucional é a característica principal do designer instrucional. Mas o que seria esta linguagem instrucional?

Como terminologicamente a instrução refere-se à técnica, ao instrumental, à transmissão de conhecimento, e instruir compreende comunicar e informar, esta pesquisa entende que a prática desta atividade é pontual e sistemática. Filatro (2008, p. 4) destaca esta parte do processo como o nível micro, em que o designer instrucional "trabalha com o design fino das unidades de estudo".

Deste modo, o designer instrucional, em diversos modelos de EaD que estão em andamento no momento, é aquele profissional multidisciplinar (normalmente não é exigida uma graduação específica, mas é necessário um diploma de curso superior) que possui experiência na área ou a certificação de um curso de design instrucional (podendo ser cursos rápidos ou especialização). Em alguns casos solicita-se conhecimento ou formação pedagógica. Este profissional pode trabalhar remotamente ou presencialmente em uma IES ou organização corporativa. O seu papel é pontuar, nos diferentes tipos de materiais didáticos que podem ser desenvolvidos na $\mathrm{EaD}$, estratégias de linguagem e métricas relacionadas ao escopo do projeto educacional para atender 0 perfil específico dos estudantes que aprendem a distância. Outra função do DI é garantir que os objetivos estabelecidos no plano de ensino, anteriormente planejados pela equipe pedagógica, sejam atendidos pelo professor autor. Como irá trabalhar diretamente com o texto, é importante que o profissional possua conhecimento textual avançado para atender as necessidades dos conteúdos didáticos, o que faz com que muitas vezes o perfil dos profissionais de Letras seja solicitado para a função.

Apesar de alguns modelos de desenvolvimento de materiais didáticos não exigirem uma formação na área em que o DI atua, observa-se que, ao tratar diretamente em um texto didático e específico de uma área de conhecimento, torna-se mais fluída e pontual as considerações ao professor autor de um DI que possui a formação na mesma área da disciplina ou curso em questão. 
Já quando se relaciona, ao perfil do designer educacional, a terminologia e etimologia das palavras educar e educacional, pode-se compreender a prática do designer educacional como indo além da instrução e pontuação de estratégias de métricas de linguagem. Ela pressupõe uma visão macro de todo o processo de desenvolvimento metodológico de um curso online, acompanhando cada fase, desde o planejamento, passando pelo desenvolvimento dos materiais e recursos didáticos, até a avaliação, verificando o que pode ser mantido e melhorado para próximas ofertas dos cursos, ou até mesmo modificado durante a fase de implementação.

No caso do $\mathrm{DE}$, a interação é questão primordial para a efetivação da sua prática. $\mathrm{Na}$ fase de planejamento, demanda diálogo com a coordenação do curso e pedagógica, a fim de definir o desenho do projeto de curso. Nas fases de desenvolvimento e implementação, requer proximidade com a equipe multidisciplinar (DI, diagramadores, revisores, tutoria, desenvolvedores web, editores de vídeos e videoconferência, entre outros), bem como com os docentes que atuaram no curso. E na etapa de avaliação, estipula mecanismos de captação de informações junto à equipe e estudantes. É importante observar que a interação também deve ser a estratégia de aprendizagem sugerida pelo DE ao docente, que atuará como mediador ativo no AVEA ou interações via videoconferência, a fim de promover o aprendizado colaborativo.

Para o perfil deste profissional, esta pesquisa compreende como necessário o conhecimento pedagógico e formação na área de conhecimento do curso desenvolvido. Isso porque, como o profissional fará parte de todo o processo, tomando decisões diretas no desenvolvimento do curso juntamente com a coordenação e docentes, faz-se necessário compreender os temas abordados para propor as melhores estratégias possíveis e os recursos de aprendizagem que facilmente serão assimilados pelos aprendizes.

Percebe-se, portanto, que apesar de igualmente destacados como parte do processo de execução de cursos de EaD, o DI e o DE possuem características e definições diferentes. Salienta-se que o DI é um elemento de instrução da linguagem do processo de desenvolvimento dos conteúdos educacionais, cabendo a ele conservar-se nesta prática. Por sua vez, o DE, por possuir particularidades mais complexas e abrangentes, tem sua atuação direcionada para o planejamento, desenvolvimento e implementação de projetos de EaD. É importante, no entanto, que esse profissional possua conhecimento em análise e adequação de linguagem textuais e midiáticas.

\section{Procedimentos Metodológicos}


A pesquisa classifica-se como científica etnográfica, trabalhada segundo uma abordagem exploratório-descritiva. Para a coleta e a análise de dados, propõe-se a técnica de métodos mistos, empregando-se práticas de pesquisa quantitativa e qualitativa com questionário de perguntas abertas e fechadas para os profissionais atuantes como designers instrucionais e designers educacionais que atuam em instituições de ensino públicas e privadas que ofertam cursos a distância, como também profissionais que trabalham em empresas do meio corporativo de desenvolvimento de materiais didáticos na $\mathrm{EaD}$, a fim de conhecer sobre as práticas, hábitos, valores e comportamentos deste profissional, e compreender 0 seu papel naquele curso/instituição. Para a compreensão sobre a forma de contratação e seleção deste profissional, bem como o cenário de atuação nas instituições pesquisadas, pretende-se realizar entrevistas semiestruturadas com os coordenadores pedagógicos e gestores de instituições de ensino superior públicas e privadas que possuem laboratórios de desenvolvimento de materiais didáticos para $\mathrm{EaD}$, como também para gestores de empresas do meio corporativo que desenvolvem material didático para cursos online.

\section{Resultados Esperados}

A pesquisa está em fase de coleta de dados. Ao utilizar de métodos de pesquisa mista: qualitativos e quantitativos, tem-se a intenção de obter dados abrangentes sobre a prática e perfil da realidade atual do profissional. O presente trabalho necessitará, primeiramente, coletar dados entre os profissionais e sua prática diária, grau de atuação, as técnicas utilizadas no tratamento da linguagem, planejamento e implementação de cursos de EaD. Para isso, pretende-se, utilizar de métodos de pesquisa descritiva, realizando um levantamento de dados em forma de questionários, com o intuito de identificar qual a visão que possuem sobre o trabalho do designer instrucional e educacional em suas respectivas organizações. Nas entrevistas com os coordenadores de desenvolvimento de materiais didáticos, pretende-se encontrar os motivos pela escolha da nomenclatura empregada para este profissional naquela instituição específica, e se há diferenciação nas atividades desenvolvidas e na relação com a prática no material didático.

\section{Considerações Finais}

Há cada ano observa-se uma crescente discussão em torno da $E a D$, suas peculiaridades e atores envolvidos. As práticas do designer instrucional e educacional surgem como vertentes desses debates, que além de propiciar novos conhecimentos e atitudes, também possibilita um (re)pensar sobre quem é esse profissional. Assim, ao conhecermos as especificidades do DI e do DE, tão importantes para este tipo de modalidade educacional, contribuímos para o desenvolvimento futuro da educação 
virtual.

Desta forma, diante das características distintas de cada designer, o instrucional e o educacional, vemos a importância de analisar como estes profissionais estão atuando nos diferentes contextos que permeiam a EaD atualmente. Cada instituição possui a sua metodologia para a educação online, contudo a atividade do DI e do DE necessitam ser esclarecidas e direcionadas a partir da análise dos seus perfis, como propõe este estudo.

\section{REFERÊNCIAS}

BRASIL. Ministério do Trabalho e Emprego. Classificação Brasileira de Ocupações. Disponível em: . Acesso em: 23 mar. 2017.

CUNHA, A. G. Dicionário etimológico da língua portuguesa. 4 ed. Lexikon: Rio de Janeiro, 2012.

FILATRO, A. Design Instrucional na prática. São Paulo: Pearson Education do Brasil, 2008.

KENSKI, V. M.; BARBOSA, A. C. L. S. Gestão de pós-graduação a distância: curso de especialização em designer instrucional para educação on-line. In: CONGRESSO LUSOBRASILEIRO DE POLÍTICA E ADMINISTRAÇÃO DA EDUCAÇÃO, Porto Alegre, 2007. Anais. Porto Alegre: Anpae, 2007. 12 p.

OLIVEIRA, J. B. A.; OLIVEIRA, M. R. Tecnologia Instrucional: um enfoque sistêmico. São Paulo, Pioneira, 1974. 